\title{
ANÁLISE DA ESTRUTURA DE DUAS UNIDADES FITOFISIONÔMICAS DE SAVANA (CERRADO) NO SUL DO BRASIL ${ }^{\prime}$
}

\author{
Alexandre Uhlmann ${ }^{2}$ \\ Franklin Galvão ${ }^{3}$. \\ Sandro Menezes Silva ${ }^{4}$
}

\section{Recebido em 23/09/1997. Aceito em 02/12/1998}

\begin{abstract}
RESUMO - (Análise da estrutura de duas unidades fitofisionômicas de savana (cerrado) no sul do Brasil). A região de Jaguariaíva, situada no Estado do Paraná. sul do Brasil, abriga os últimos remanescentes de savana no Estado e pode ser considerada como marco do limite meridional de distribuição deste tipo de vegetação no Brasil. O Parque Estadual do Cerrado (24.09. S: $50^{\circ} 18^{\circ}$ WG) foi objeto deste estudo em que se analisou a estrutura da vegetação de duas formas fisionômicas de savana, o campo cerrado e o cerrado sensu stricto. Estas duas formas são predominantes na área do Parque, ainda que este não seja coberto exclusivamente por vegetação savânica. Vinte parcelas com dimensões de $200 \mathrm{~m}^{2}(20 \mathrm{X} \mathrm{10m})$ foram alocadas sistematicamente $\mathrm{em}$ cada unidade fisionômica. onde todo indivíduo com perímetro basal (PB) igual ou maior a $15 \mathrm{~cm}$ foi amostrado. Os resultados do levantamento apontaram para pequeno número de espécies lenhosas em ambos os tipos fisionômicos ( 33 espécies no cerrado sensu stricto e 18 no campo cerrado). As espécies mais importantes foram virtualmente as mesmas em ambas as formas fisionômicas, destacando-se Byrsonima coccolobifolia. Acosmium subelegans, Couepia grandiflora e Stryphnodendron adstringens. A densidade total, dominância total e diversidade foram mais elevadas no cerrado sensu stricto. Além disso, ficou aparente a maior semelhança florística com as savanas de São Paulo, especialmente aquelas situadas ao sul deste Estado.
\end{abstract}

Palavras-chave - cerrado, savana, fitossociologia, Paraná

ABSTRACT - (Structural analysis of two physiognomic types of savanna ("cerrado") from southern Brazil). The Jaguariaiva region is located at Parana State. southern Brazil, and it keeps up the last remnants of savanna vegetation in the State. Thus. it should be considered a mark of the meridional distribution limit of this vegetation type in Brazil. The Parque Estadual do Cerrado (24.09' S; $50^{\circ} 18^{\prime}$ WG), whose vegetation is not solely composed by savanna forms, was the object of this study that analysed the vegetation of two dominant savanna physiognomic types (cerrado sensu stricto and campo cerrado). Twenty quadrats of $200 \mathrm{~m}^{2}(20 \mathrm{X} 10 \mathrm{~m})$ were sistematicaly established in each physiognomic unit, and all the individuals having Basal Perimeter (BP) over $15 \mathrm{~cm}$ were sampled. The survey results indicated a low number of woody species in both units ( 33 species in cerrado sensu stricto and 18 in campo cerrrado). Most important species were virtually the same for both units, specially Byrsonima coccolobifolia, Acosmium subelegans, Couepia grandiflora and

Parte de Dissertação de Mestrado do primeiro autor

- Departamento de Botânica. IB, UNICAMP. C. Postal 6109. CEP 13,083-970, Campinas, SP, Brasil. Bolsa CNPq. e-mail: uhlmann @garoupa.bio.ufpr.br

${ }^{3}$ Departamento de Silvicultura e Manejo. UFPR, rua Bom Jesus. 650. CEP 80.030-010, Curitiba, PR, Brasil. e-mail: fgalvao@floresta.ufpr.br

+ Departamento de Botânica. UFPR. C. Postal 19.031. CEP 81531-970. Curitiba, PR. Brasil. e-mail: menezes@garoupa.bio.ufpr.br 
Stryphnodendron adstringens. The total density, total dominance and diversity were higher in cerrado sensu stricto. Moreover, there was apparently a higher floristic resemblance with savannas of São Paulo State, specially those located in the South of the State.

Key words - cerrado, savanna, phytosociology. Paraná State

\section{Introdução}

As savanas ocupam área aproximada de 23 milhões de $\mathrm{km}^{2}$ no mundo, distribuídas entre as florestas equatoriais e as latitudes médias e semi-desertos (Cole 1986). No Brasil, a savana (cerrado) é encontrada principalmente sobre os chapadões do interior dos Estados de Mato Grosso, Mato Grosso do Sul, Goiás, Tocantins e Minas Gerais, mas também nos tabuleiros costeiros de Pernambuco, Bahia, Sergipe e Alagoas, no norte do Amazonas e no Amapá (Cole 1986) e como "ilhas" disjuntas nos Estados de São Paulo e Paraná (Eiten 1994).

A vegetação das savanas possui aspecto xeromórfico (Coutinho 1978; Eiten 1994), estando comumente associada a áreas onde predomina o tipo climático Aw de Köppen, ou seja, com estação seca definida (Cole 1986). Na América do Sul, encontra-se nos planaltos interioranos, sobre solos pobres, bem drenados, arenosos, lixiviados e com alta concentração de alumínio e ferro (Cole 1986).

Estudos tratando aspectos do solo e clima na região das savanas levantaram muitos argumentos em favor da possível origem pedológica das savanas (Arens 1958; Goodland 1979), o que impulsionou diversos trabalhos voltados ao levantamento quali-quantitativo da vegetação e de fatores abióticos relacionados. Coutinho (1978) argumentou que a diversidade de formas fisionômicas da savana estariam relacionadas a um gradiente florísticoestrutural, reafirmado por Goodland (1979). Eiten (1994) demonstrou haver variedade de formas estruturais, inclusive dentro de uma mesma unidade fisionômica do cerrado.

Mediante abordagem mais ampla, Ratter \& Dargie (1992) demonstraram ser a latitude um fator de forte influência na determinação da similaridade florística entre áreas de savana. Estes mesmos aspectos foram discutidos também por Castro (1994).

Apesar de a savana ter sido objeto de intensos estudos no Brasil, os remanescentes do sul do País não foram objeto da mesma atenção. Para o nordeste do Paraná, região em que se insere a área do presente estudo, as informações praticamente inexistem. Nessa região, as savanas distribuem-se em áreas de clima temperado (Cfb de Köppen), podendo representar relictos de condição climática pretérita mais seca (Maack 1968, Leite 1994). Embora tal condição tenha chamado a atenção de alguns autores, seus trabalhos dispõem tão somente de descrições gerais da vegetação (Maack 1968; Leite, 1994). Tendo em vista esta carência de dados, o estudo ora apresentado pretendeu diagnosticar a estrutura de duas unidades fisionômicas de savana (campo cerrado e cerrado sensu stricto), bem como discutir alguns aspectos da ocorrência deste tipo de vegetação no Estado do Paraná.

\section{Material e métodos}

Área de estudo - O Parque Estadual do Cerrado, criado pelo Governo do Estado do Paraná pelo Decreto n 1232 de 27 de março de 1992, compreende área de 426,62 
ha de uma chapada arenítica a cerca de $7 \mathrm{~km}$ a nordeste do núcleo urbano do município de Jaguariaíva ( $24^{\circ} 09^{\prime} \mathrm{S} ; 50^{\circ} 18^{\prime}$ WG - Fig. 1). A região de Jaguariaíva está inserida em zona sempre úmida, de clima temperado (tipo Cfb de Köppen), cujo mês mais quente registra temperaturas médias abaixo de $22^{\circ} \mathrm{C}$ e nos demais onze meses, acima de $10^{\circ} \mathrm{C}$, com registro de mais de cinco geadas noturnas por ano (Tab. 1). Predominam ventos dos quadrantes sulinos $(38,1 \%)$, enquanto os ventos portadores de chuvas dos quadrantes setentrionais somam 29,2\% do total. Em 43 anos de observações, houve média anual de 129 dias chuvosos e 236 secos (Maack 1968).

Localizada no segundo planalto paranaense (Maack 1968), a região possui formas de relevo suavemente arredondadas (Bigarella et (al. 1966), exceto pelo encaixamento característico da rede de drenagem (Hermann \& Rosa 1990). Há o predomínio de rochas sedimentares paleozóicas do grupo Paraná (formação Furnas e formação Ponta Grossa) e da formação Itararé (Maack 1968). São característicos os arenitos grosseiros da formação Furnas (Bigarella et al. 1966), sobre os quais a formação Ponta Grossa, com seus sedimentos de granulação fina, sobrepõe-se concordantemente (Kaul 1990). Na região, afloram ainda rochas sedimentares da formação Itararé (Schobbenhaus et al. 1984).

$\mathrm{Na}$ área do Parque, o relevo é pouco movimentado (ondulado a suave ondulado), com altitude variável entre 800 até $900 \mathrm{~m}$ s.n.m., mas também incluindo áreas de declives acentuados nas proximidades do vale do rio Jaguariaíva, onde a altitude chega à $750 \mathrm{~m}$ s.n.m. (Uhlmann 1995). A maior parte da área é dominada por latossolos de baixa fertilidade natural, principalmente o Latossolo Vermelho-Escuro, que varia de álico até distrófico e de textura média até argilosa (Uhlmann et al. 1997), predominante para a região (EMBRAPA 1984). O Latossolo Vermelho-Escuro distribui-se nas porções mais planas e elevadas e o Latossolo Vermelho-Amarelo, nas áreas mais inclinadas do terço inferior das encostas. Nas regiões próximas aos rios Jaguariaíva e Santo Antônio, que compõem os limites leste e norte do Parque, respectivamente, ocorrem solos hidromórficos e semi-hidromórficos, além de solos litólicos e afloramentos de rocha (Uhlmann et al. 1997).

O Parque contém dois grupos básicos de fitofisionomias: um savânico e outro florestal (Fig. 1). O grupo savânico varia do campo limpo/campo sujo, passando pelo campo cerrado até o cerrado sensu stricto (ver Coutinho 1978 e Eiten 1994 para definições de formas fisionômicas). As formas florestais variam de uma área de ecótono floresta/savana até as florestas de galeria. Há ainda outras formas de vegetação associadas aos solos hidromórficos e semi-hidromórficos e, em alguns locais, aos solos litólicos. Tratam-se de formas campestres compostas basicamente por um estrato herbáceo graminóide (Uhlmann 1995; Uhlmann et al. 1997). O campo cerrado caracteriza-se pela presença de indivíduos lenhosos xeromórficos esparsos (cobertura arbórea de 10$30 \%)$ e baixos ( $1-2 \mathrm{~m})$ em meio a um estrato herbáceo predominantemente graminóide. O cerrado sensu stricto possui indivíduos lenhosos distribuídos de forma mais densa (cobertura arbórea de até $60 \%$ ) e dẹ maior altura (3-4m). O estrato herbáceo é heterogêneo com muitas espécies de subarbustos e ervas em meio às ervas graminóides. As espécies arbóreas apresentavam em seus troncos marcas evidentes de fogo. O histórico da incidência de queimadas no Parque, no entanto, é desconhecido, em virtude de sua recente implantação. A última queimada registrada ocorreu pouco após o término 

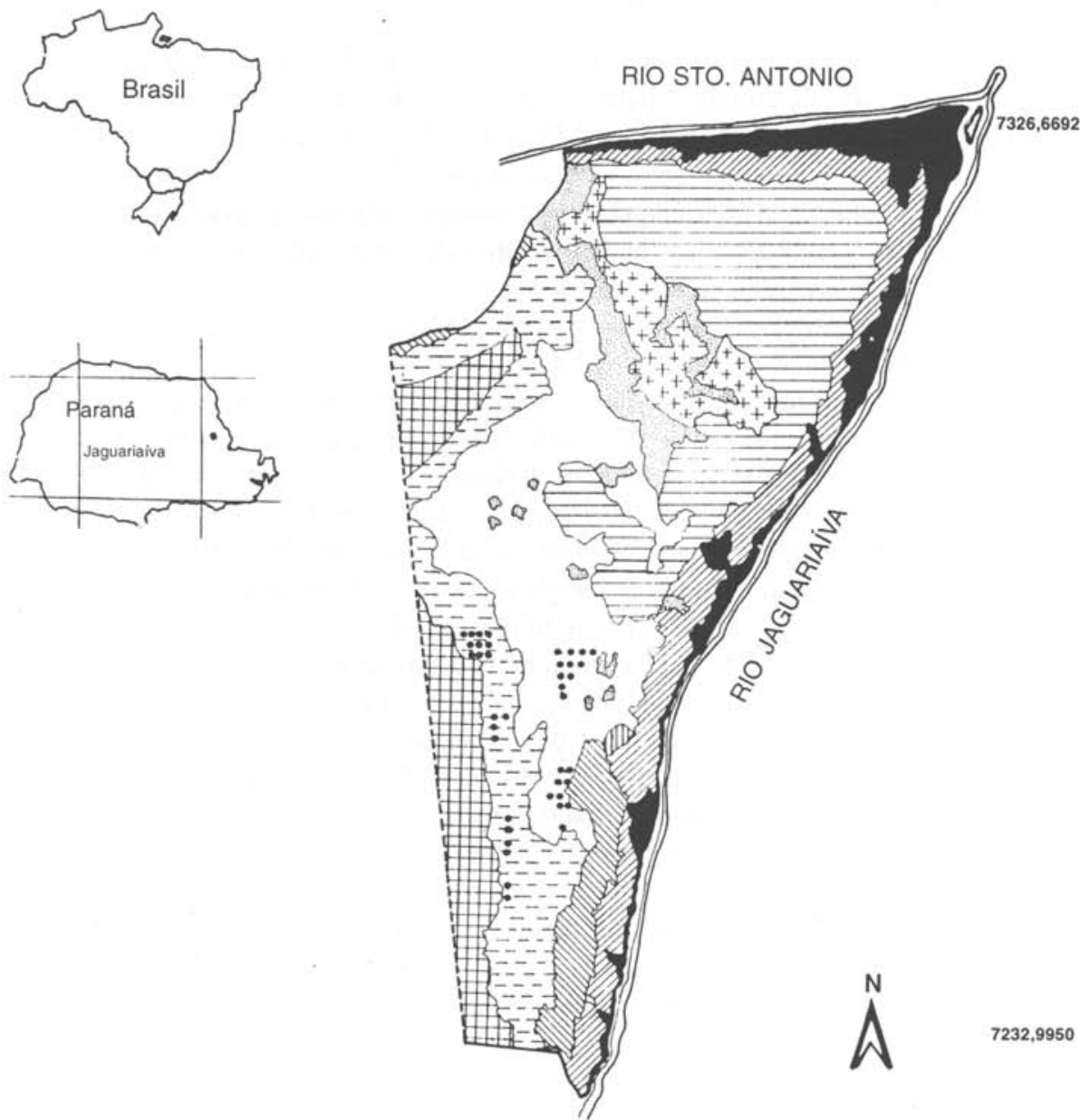

LEGENDA

CONVENÇŌES

Campo Limpo/Campo Sujo
Cerrado "Sensu Stricto"
$\square$ Floresta Ecotonal
$\square+3$ Floresta Ecotonal (Alterada)

MU Campo Higro/Hidrófilo

Floresta de Galeria

ÁREA: 420,1007 ha

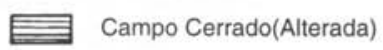

$=$ Rios

[1]王 Plantio de Exóticas • Localizaçăo das Parcelas

VIIIA Afloramentos de Rochas

Solos Rasos

Figura 1. Localização do município de Jaguariaíva no Estado do Paraná c mapa de vegetação do Parque Estadual do Cerrado. 
Tabela 1 - Temperaturas médias, máximas e mínimas $\left({ }^{\circ} \mathrm{C}\right.$ ). frequiência de geadas (dias/ano) e precipitações médias (mm) em Jaguariaíva. PR (médias e média das máx.: 1918-44; média das mín.: 1946-61; precip.: 1918-44 e 1946-61)

\begin{tabular}{|c|c|c|c|c|c|}
\hline \multirow[t]{2}{*}{ Meses } & \multicolumn{3}{|c|}{ Temperatura " $\mathrm{C}$} & \multirow{2}{*}{$\begin{array}{l}\text { Frequiência de } \\
\text { geadas }\end{array}$} & \multirow{2}{*}{$\begin{array}{c}\text { Precipitação } \\
\text { média } \\
(\mathrm{mm})\end{array}$} \\
\hline & Média & $\begin{array}{l}\text { Média das } \\
\text { Máximas }\end{array}$ & $\begin{array}{l}\text { Médias das } \\
\text { Mínimas }\end{array}$ & & \\
\hline Jan & 21,3 & 27,1 & 16.9 & 0 & 225,4 \\
\hline Fev & 21,1 & 26.7 & 16.3 & 0 & 159,0 \\
\hline Mar & 20,1 & 26,1 & 12.9 & 0 & 117,2 \\
\hline Abr & 17,5 & 23,7 & 10.3 & 0 & 79,3 \\
\hline Mai & 14,1 & 22,0 & 8.9 & 1.8 & 80,0 \\
\hline Jun & 13,7 & 20,8 & 7.8 & 3,1 & 88,1 \\
\hline Jul & 13,4 & 20.8 & 9.3 & 2,4 & 61,3 \\
\hline Ago & 15,3 & 22,6 & 11.2 & 2,1 & 69,6 \\
\hline Set & 16.7 & 23.5 & 13.1 & 0.9 & 106,8 \\
\hline Out & 18,1 & 24,2 & 14.2 & 0 & 129,6 \\
\hline Nov & 19.7 & 25.0 & 15.6 & 0 & 127,8 \\
\hline Dez & 20,8 & 26.6 & 16.9 & 0 & 139,1 \\
\hline Média anual & 17.65 & 24,1 & 12.8 & 10.3 & 1383,2 \\
\hline
\end{tabular}

Fonte: Maack (1968)

do levantamento realizado para este estudo. Antes de sua implantação em 1992, o Parque possuía uso pouco intensivo na pecuária.

Procedimento metodológico - Para a condução do levantamento fitossociológico foram considerados o campo cerrado e o cerrado sensu stricto. Em cada categoria, 20 parcelas retangulares de $200 \mathrm{~m}^{2}(20 \times 10 \mathrm{~m})$ foram alocadas segundo um modelo sistemático de amostragem. Adotou-se como critério de inclusão o perímetro basal (PB) igual ou superior a $15 \mathrm{~cm}$. Quando o indivíduo apresentava dois ou mais caules, ao menos um deveria ter o perímetro mínimo para que fosse amostrado. Atendido este requisito, todos os caules seriam medidos. Para identificar se dois ou mais caules pertenciam ao mesmo indivíduo, escavou-se o solo à pouca profundidade. Quando a conexão não foi identificada mediante tal procedimento, os caules foram considerados indivíduos separados. Se o indivíduo estivesse situado no limite da parcela, seria amostrado somente aquele que estivesse com a metade do diâmetro do tronco no interior da parcela e situado nas faces inferior e esquerda da mesma. Os indivíduos mortos não foram considerados no tratamento de dados.

Para cada indivíduo amostrado foram obtidos os valores de altura total e perímetro basal. A determinação do material botânico foi feita em campo, ou através da coleta do material estéril ou fértil, que, levado ao Herbário do Departamento de Botânica da Universidade Federal do Paraná (UPCB), foi herborizado, determinado e incorporado à coleção. Para a definição do hábito do indivíduo coletado, seguiu-se o exposto por Warming (1908). A definição, entretanto, somente se aplica ao indivíduo coletado, o que não significa que todos os indivíduos da população da espécie possuam o mesmo hábito. Seguiu-se o sistema de classificação de Cronquist (1988) e, para a abreviatura dos nomes de autores, adotou-se Brummitt \& Powell (1992).

O tratamento dos dados foi feito em computador através de um pacote de programas (FITOPAC v. 1.0) de autoria do Prof. Dr. George J. Shepherd, resultando na 
estimativa dos parâmetros de densidade, dominância e freqüência, além dos índices de importância, cobertura, similaridade e diversidade (Mueller-Dombois \& Ellenberg 1974; Magurran 1989).

Os dados de altura e diâmetro dos indivíduos amostrados foram transformados através de vários métodos $\left(\log _{\mathrm{n}}, \log _{10}, \log _{2}\right.$, arco-seno, raiz quadrada) para que estes fossem ajustados à curva de distribuição normal. Uma vez verificado o ajuste à curva normal (teste de Kolmogorov-Smirnoff), os dados foram comparados através do teste "T". Quando não se obteve o ajuste, foi aplicado um teste estatístico não-paramétrico ("U" de Mann-Whitney). Para a verificação de diferenças estatisticamente significativas de densidade e dominância, bem como para a verificação de diferenças de densidade e dominância para as espécies mais representativas entre as unidades fisionômicas, aplicou-se o teste "U" de Mann-Whitney. Os procedimentos de transformação dos dados e testes estatísticos são descritos em Kirk (1968). A diversidade e a eqüidade das duas unidades fisionômicas foram comparadas através do cálculo do estatístico "T", conforme descrito em Magurran (1989) e Pielou (1975).

\section{Resultados}

Os dados reunidos na Tab. 2 demonstram que o cerrado sensu stricto caracterizouse por ter maior densidade, dominância, número de espécies lenhosas e diversidade. Além disso, este mesmo conjunto de dados indica a maior altura média dos indivíduos do cerrado sensu stricto, embora o diâmetro médio não tenha apresentado diferenças significativas. A Fig. 2 apresenta sinteticamente dados que reforçam tal fato. Ainda que se possa observar a maior representatividade dos indivíduos em classes superiores a $10 \mathrm{~cm}$ no cerrado sensu stricto, em torno de $70 \%$ dos indivíduos em ambas as categorias concentram-se na classe de $5-10 \mathrm{~cm}$. A aplicação de teste qui-quadrado resulta em diferença não significativa $(\mathrm{p}<0,33)$ quando comparadas as distribuições entre as duas categorias. A Fig. 3 dispõe os dados de modo a ilustrar a concentração de indivíduos nas classes de 1 a $3 \mathrm{~m}$ em ambas as categorias, havendo, porém, representatividade marcante de indivíduos nas classes superiores a $3 \mathrm{~m}$ no cerrado sensu stricto. A aplicação de um teste qui-quadrado aponta a presença de diferença estatisticamente significativa $(\mathrm{p}<0,01)$, se comparada a distribuição entre as duas categorias.

No Parque, as 18 espécies encontradas no campo cerrado também foram observadas em maior ou menor grau de importância no cerrado sensu stricto, porém, nesta unidade fisionômica, outras 15 espécies foram encontradas (Tab. 3). Disso resultou que os índices de similaridade de Jaccard e Sörensen entre as duas unidades fisionômicas equivaleram a $55 \%$ e $71 \%$, respectivamente.

Seis espécies responderam por aproximadamente $84 \%$ do valor de importância no campo cerrado (Tab. 4). Essas espécies (Stryphnodendron adstringens, Byrsonima coccolobifolia, Couepia grandiflora, Annona crassiflora, Acosmium subelegans e Anadenanthera peregrina) totalizaram $91 \%$ da estimativa de densidade e $86 \%$ da dominância total. Caracterizou-se, portanto, uma fisionomia homogênea, marcada pela abundância de Stryphnodendron adstringens. Já as espécies pouco abundantes, como Dalbergia miscolobium, Symplocos lanceolata e Ouratea spectabilis, cada qual com apenas três indivíduos na amostra, agregaram até $10 \%$ do percentual de cobertura. 
Tabela 2. Comparação entre as características estruturais e de riqueza e diversidade de espécies obtidas para o campo cerrado e o cerrado sensu stricto no Parque Estadual do Cerrado, Jaguariaíva, PR

\begin{tabular}{lccccc}
\hline Parâmetros & $\begin{array}{c}\text { Campo } \\
\text { Cerrado }\end{array}$ & $\begin{array}{c}\text { Cerrado } \\
\text { sensu stricto }\end{array}$ & Estatístico & $\mathrm{P}$ \\
\hline Densidade total (ind/ha) & 857.50 & 1372.50 & $\mathrm{U}=$ & 74,00 & $<0.000654$ \\
Dominância Absoluta (m²/ha) & 5.62 & 12.37 & $\mathrm{U}=$ & $-4,22$ & $<0.000025$ \\
Diâmetro médio (cm) & 8.44 & 9.49 & $\mathrm{U}=87433.50$ & $<0.072639$ \\
Altura média (m) & 2.02 & 2.96 & $\mathrm{~T}=$ & -12.65 & $<10-6$ \\
Número de espécies & 18 & 33 & - & - & \\
Índice de Shannon (nats/ind.) & 1.901 & 2.788 & $\mathrm{~T}=$ & 11.77 & $<10-6$ \\
Eqüidade (nats/ind.) & 0.658 & 0.797 & $\mathrm{~T}=$ & 59,30 & $<10-6$ \\
Número de famílias & 15 & 27 & - & - & \\
Índice de Shannon p/ família (nats/ind) & 1.748 & 2.569 & $\mathrm{~T}=$ & 0.427794 & $<0.669390$ \\
\hline
\end{tabular}

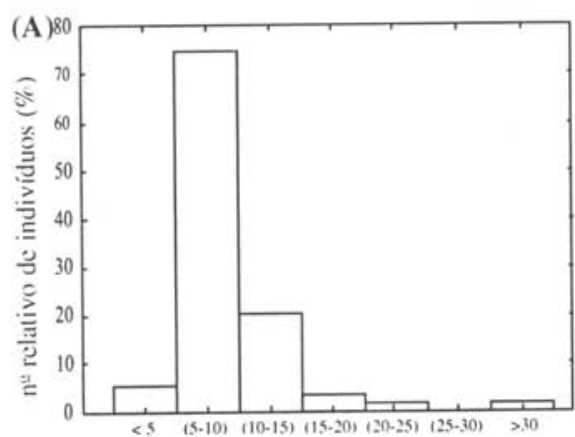

Classes de diâmetro $(\mathrm{cm})$

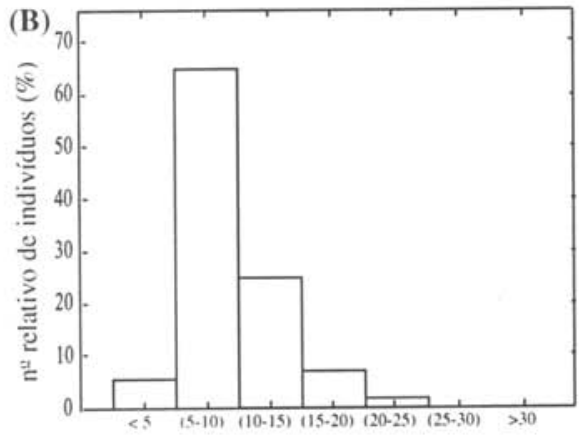

Classes de diâmetro $(\mathrm{cm})$

Figura 2. Comparação da frequêencia dos indivíduos amostrados no campo cerrado (A) e cerrado sensu stricto (B) em intervalos de classes de diâmetro.

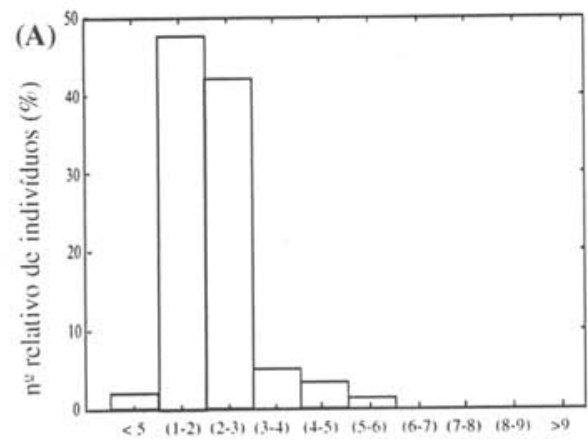

Classes de altura $(\mathrm{m})$

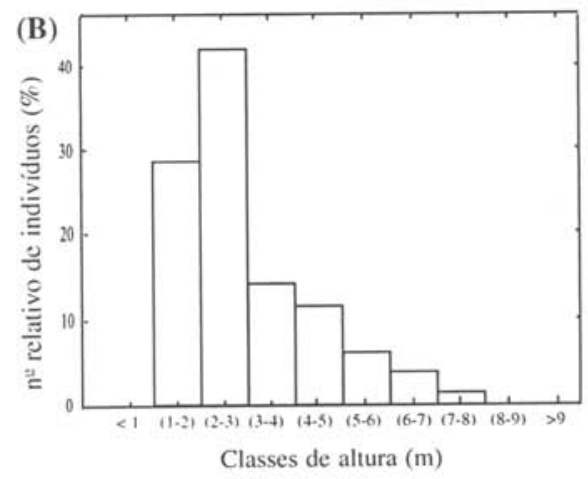

Figura 3. Comparação da frequiência dos indivíduos amostrados no campo cerrado (A) e cerrado sensu stricto (B) em intervalos de classes de altura. 


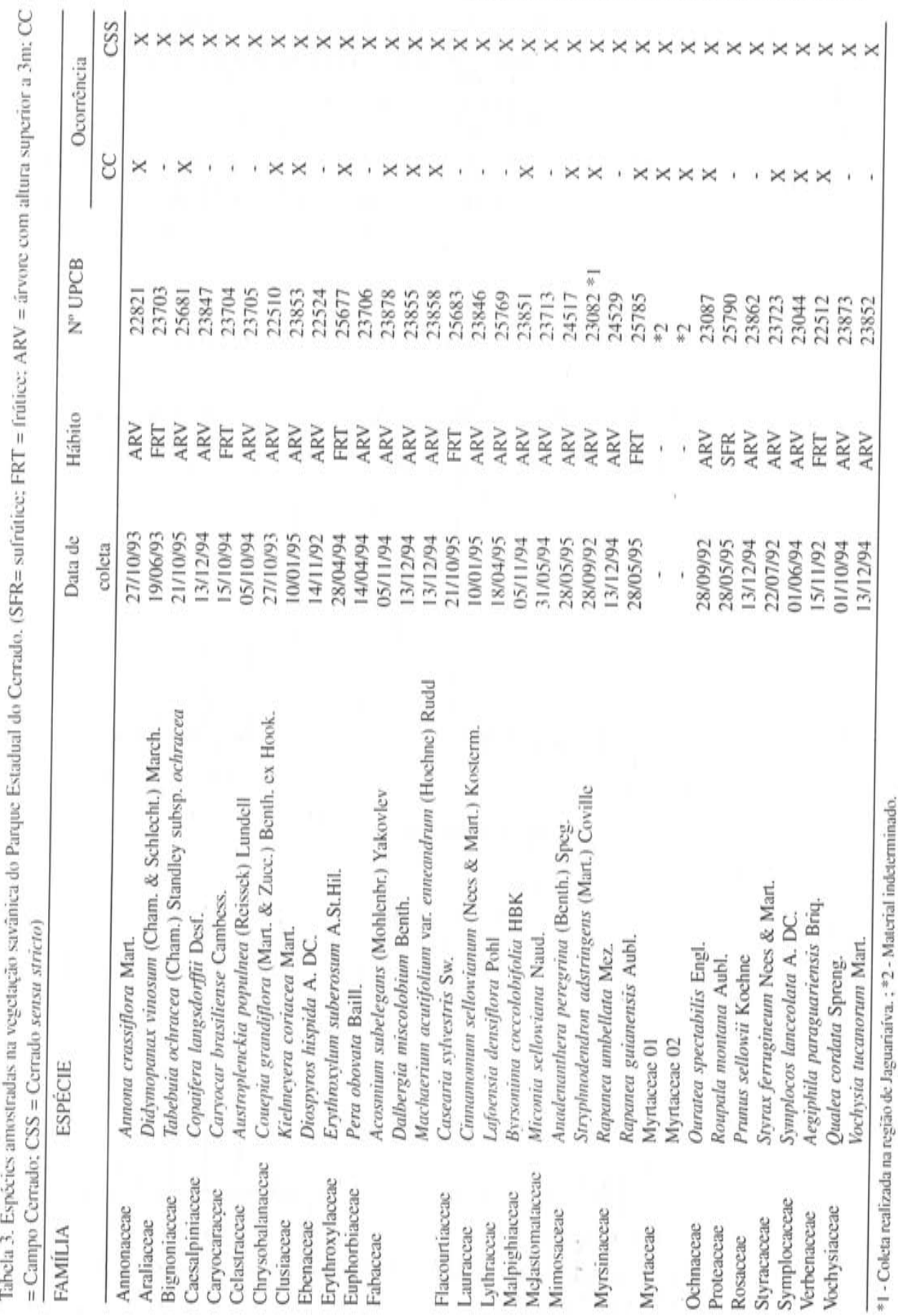




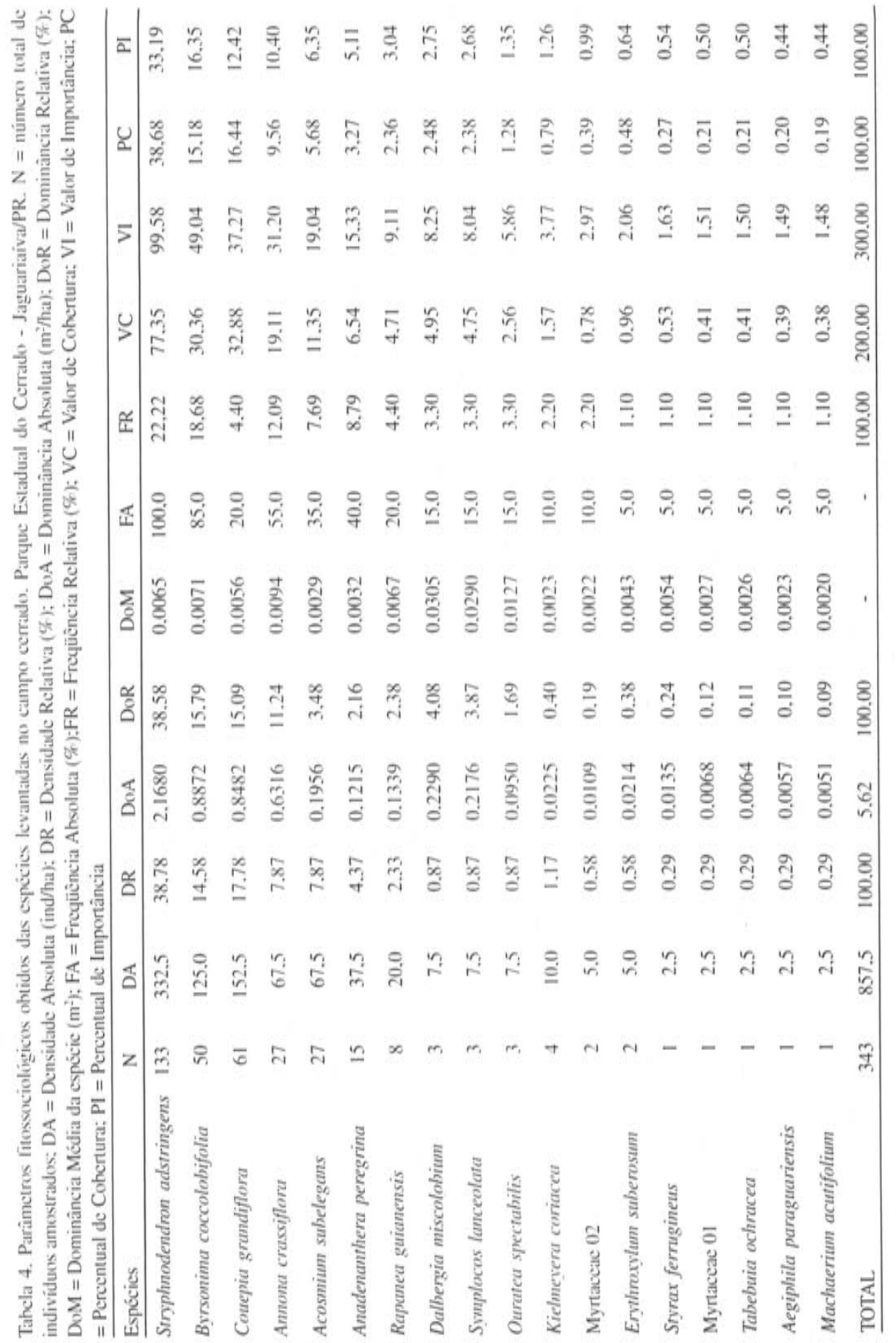


Stryphnodendron adstringens, Byrsonima coccolobifolia, Couepia grandiflora e Annona crassiflora somaram pouco mais de $80 \%$ da dominância relativa, detendo no conjunto, $77 \%$ do total do valor de cobertura. A única espécie amostrada em todas as parcelas foi $S$. adstringens, corroborando sua importância sociológica. A maior parte das espécies foi pouco abundante, sendo onze espécies (60\% do total) representadas por menos que cinco indivíduos na amostra. Estas somam apenas $8,8 \%$ do percentual de importância.

Byrsonima coccolobifolia, Anadenanthera peregrina, Couepia grandiflora, Stryphnodendron adstringens, Acosmium subelegans e Lafoensia densiflora foram as espécies mais importantes no cerrado sensu stricto (Tab. 5). De imediato, constata-se que, salvo pela última, tratam-se das mesmas espécies de maior importância no campo cerrado. A importância sociológica de cada uma dessas espécies, no entanto, foi diluída em relação àquela situação descrita para o campo cerrado, pois aquelas seis espécies juntas somaram $55 \%$ do percentual de importância. Aquelas mesmas espécies somaram $65 \%$ da densidade total, embora as populações de Annona crassiflora, Ouratea spectabilis, Diospyros hispida, Miconia sellowiana, Caryocar brasiliense, Rapanea guianensis, Tabebuia ochracea, Myrtaceae 1 e Austroplenckia populnea também tenham sido bem numerosas e, junto com aquelas já citadas, tenham acumulado $89 \%$ do total da densidade e $86 \%$ da dominância. Nenhuma espécie ocorreu em $100 \%$ das parcelas.

No cerrado sensu stricto algumas espécies contribuíram para que houvesse distribuição marcante de indivíduos nas classes de maior altura, destacando-se Tabebuia ochracea, Ouratea spectabilis, Annona crassiflora, Stryphnodendron adstringens, Austroplenckia populnea, Cinnamomum sellowianum, Miconia sellowiana e Dalbergia miscolobium, que apresentaram mais que $50 \%$ dos indivíduos amostrados com altura superior a $3 \mathrm{~m}$. Já no campo cerrado, a maior parte dos indivíduos foi representada por arbustos de pequeno tamanho, havendo poucas espécies que se sobressaíram por seu porte.

Aplicando-se o teste " $U$ " para comparar as populações das seis espécies mais importantes do campo cerrado com as suas respectivas populações no cerrado sensu stricto, verificou-se a presença de significativa diferença estatística para a densidade estimada de Stryphnodendron adstringens ( $\mathrm{p}<0,000376)$, Byrsonima coccolobifolia $(\mathrm{p}$ $<0,004908)$ e Anadenanthera peregrina $(0,000056)$. Em contrapartida, nenhuma diferença estatística foi verificada para Annona crassiflora $(\mathrm{p}<0,42)$. Couepia grandiflora $(\mathrm{p}<$ 0.06 ) e Acosmium subelegans ( $\mathrm{p}<0,24)$. O mesmo procedimento aplicado para os dados de dominância resultaram em diferença significativa novamente para Stryphnodendron adstringens ( $\mathrm{p}<0,000922)$, Byrsonima coccolobifolia $(\mathrm{p}<0,006561)$ e Anadenanthera peregrina $(\mathrm{p}<0,000042)$ e nenhuma diferença para Annona crassiflora $(\mathrm{p}<0,75)$, Couepia grandiflora $(\mathrm{p}<0,051)$ e Acosmium subelegans $(\mathrm{p}<0,17)$.

\section{Discussão}

As observações feitas anteriormente denotam a existência de várias diferenças estruturais entre as unidades fisionômicas tratadas no estudo, há muito expostas por vários autores (Coutinho 1978; Goodland 1979; Eiten 1994). Embora Eiten (1994) tenha delimitado objetivamente as formas fisionômicas, os argumentos de Goodland (1979) demonstraram não haver limites discretos entre elas. De fato, limites bem 


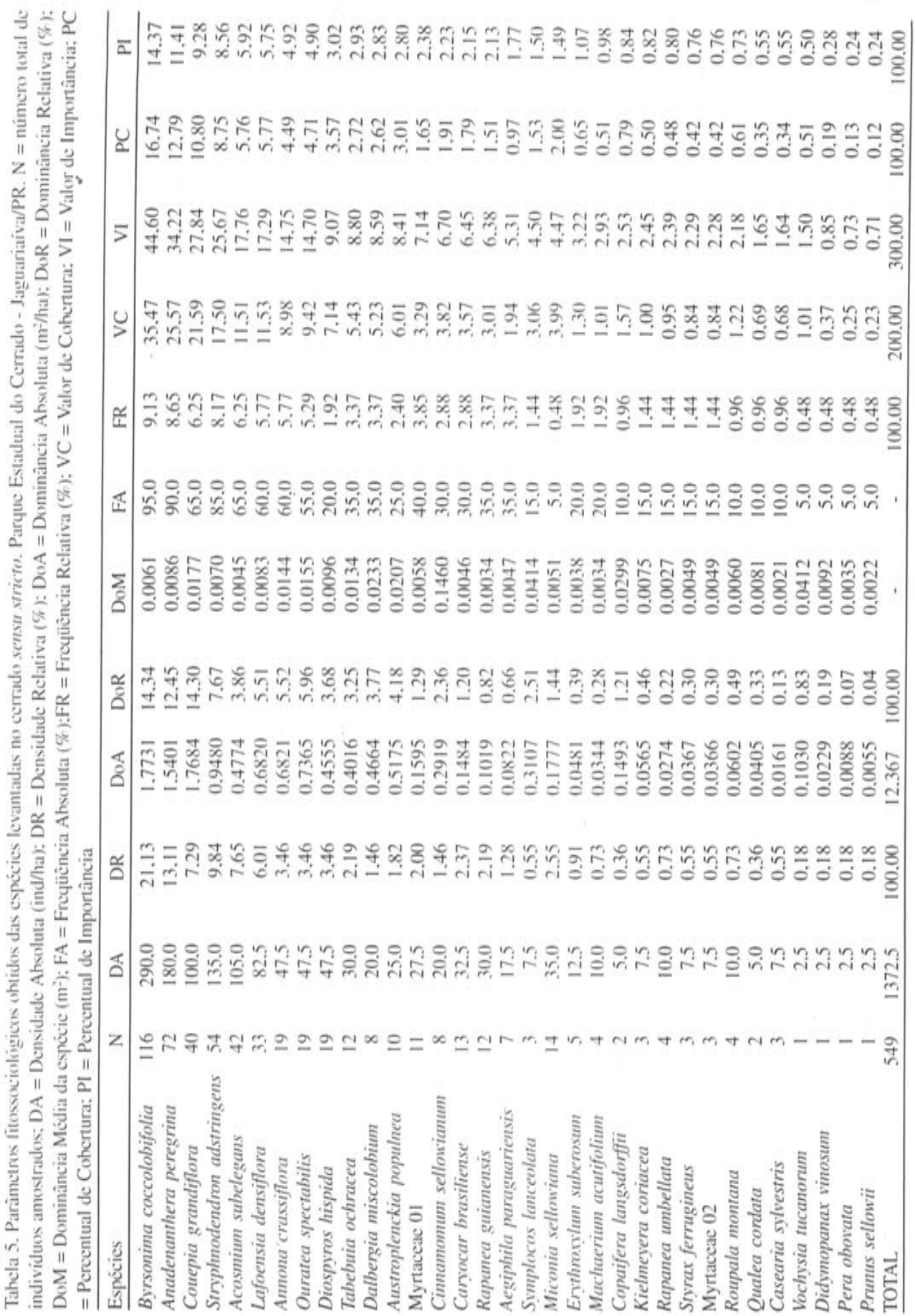


definidos no Parque somente foram observados entre as formas savânicas e outras fisionomias de vegetação, como as florestas e os campos higro/hidrófilos. No primeiro caso, é possível que o fogo provoque transição abrupta da floresta para a savana, pois impede o estabelecimento apropriado das espécies florestais, mas não as do cerrado (Ferri 1973). No segundo caso, as condições de hidromorfia dos solos impedem o estabelecimento da vegetação lenhosa da savana (Oliveira Filho et al. 1989; Eiten 1994; Uhlmann et al. 1997). Salvo por estes casos, há somente transições gradativas entre as formas fisionômicas de savana.

Assim, as definições de unidades fisionômicas (Eiten 1994) são, na verdade, modelos que tentam compartimentalizar a vegetação da savana, e as unidades fisionômicas tratadas neste estudo, a despeito de suas comprovadas diferenças estruturais, devem ser observadas sob tal ótica. Parece ser mais apropriado tratar a savana como um gradiente contínuo de zonas de vida ou biócoros, idéia introduzida por Coutinho (1978). Talvez a mais evidente prova da relação existente entre as duas categorias seja a paridade florística das espécies mais abundantes.

De fato, as unidades fisionômicas mostraram-se muito aproximadas floristicamente, como indicaram os índices de similaridade aplicados. Mueller-Dombois \& Ellenberg (1974) citaram que duas associações vegetais podem ser consideradas similares se o índice de Jaccard estiver entre $25 \%$ e $50 \%$.

Analisando-se os dados de modo mais minucioso, os testes estatísticos aplicados para as populações das seis espécies mais importantes comprovam que, embora algumas destas permaneçam numericamente inalteradas, três tiveram flutuações de densidade e dominância entre as duas categorias. Se por um lado Stryphnodendron adstringens possui maior densidade e dominância no campo cerrado, por outro, as populações de Byrsonima coccolobifolia e Anadenanthera peregrina são mais abundantes no cerrado sensu stricto. Isto indica que há uma restrição à ocupação do espaço para algumas espécies, ao passo que outras são favorecidas. É importante lembrar que a aplicação de teste não-paramétrico, que se baseia na estimativa da mediana populacional, acaba por ser influenciado pelos padrões de distribuição espacial dos indivíduos entre as unidades amostrais (Kirk 1968).

Algumas espécies de baixa representatividade no campo cerrado possivelmente encontraram condições mais favoráveis no cerrado sen.su stricto. A julgar pelo número de indivíduos encontrados nesta última unidade fisionômica, Ouratea spectabilis, Tabebuia ochracea, Dalbergia miscolobium, Myrtaceae 1 e Rapanea guianensis formaram conjunto de espécies que encontraram, no cerrado sensu stricto, melhores condições para seu estabelecimento. Além daquelas espécies, vale mencionar a presença de Copaifera langsdorffii, Vochysia tucanorum, Cinnamomum sellowianum, Miconia sellowiana, Rapanea umbellata, amostradas somente no cerrado sensu stricto. A despeito da desprezível abundância, a ocorrência destas é importante por serem espécies não xeromórficas, consideradas por Rizzini (1963) como acessórias à flora savânica e que foram observadas mais freqüentemente associadas às formações florestais presentes no Parque.

Somam-se a isso o maior número de espécies e maior diversidade do cerrado sensu stricto, oferecendo argumentos favoráveis à hipótese de que esta unidade 
fisionômica está compreendida em um ambiente mais apropriado ao estabelecimento de algumas espécies. Parece razoável levantar a hipótese de que no campo cerrado os condicionantes ambientais seriam menos favoráveis, interferindo negativamente no estabelecimento das mesmas. Adicionando elementos a esta hipótese, é possível que estes eventos venham a levar à supremacia de algumas poucas espécies, o que explicaria a dominância de número reduzido de espécies no campo cerrado.

Quais são estas condições ainda é pergunta a ser respondida, contudo algumas hipóteses merecem ser discutidas. Há muito que os estudos que discutem a origem das savanas têm apoiado a idéia de que a variação fisionômica da vegetação tem explicação na influência do fator pedológico. Goodland (1979) e Ribeiro et al. (1982) estão entre os vários autores que analisaram a variação da vegetação savânica sob perspectiva de suas interações com variações pedológicas. No Parque de Jaguariaíva, entretanto, Uhlmann et al. (1997) não encontraram explicação convincente para a variação observada, até mesmo para a presença de forma florestal de vegetação, tendo em vista a homogeneidade pedológica local. Os autores preferiram pautar a sua discussão em fatores de ordem geomorfológica e de outras características relacionadas, como a água subsuperficial, como Oliveira Filho et al. (1989) já haviam citado.

Além disso, no campo cerrado, a estrutura da vegetação favoreceria a atuação do fogo e seus efeitos seriam mais drásticos (Kauffman et al. 1994), o que impossibilitaria a instalação de espécies em razão da menor resistência aos seus efeitos (Eiten 1994; Durigan et al. 1994). Pode-se deduzir que a habilidade das espécies em resistir aos efeitos do fogo derivariam, em primeiro momento, da espessa camada de súber que reveste os troncos e, em segundo momento, da capacidade de emitir rebrotas após a morte parcial ou total da porção aérea. Neste caso, a competição entre as espécies seria determinada não somente pela habilidade das espécies no aproveitamento dos recursos, mas também pela sua capacidade de resistir ao fogo (Durigan et al. 1994). Isto poderia implicar em maior dificuldade na instalação de espécies não xeromórficas, particularmente no campo cerrado, conforme exposto anteriormente. Pode-se imaginar que os danos provocados no campo cerrado sejam maiores em virtude de sua maior massa combustível (Kauffman et al. 1994). Isto levaria à marcante redução do porte $\mathrm{e}$ densidade na vegetação, ainda que as queimadas tenham a capacidade de se alastrarem por todo o Parque, atingindo indiscriminadamente todas as formas de vegetação, exceto as florestais, conforme observado em 1994. Bilbao et cl. (1996) reforçaram esta idéia quando expõem a hipótese de relações de circularidade entre a estrutura da vegetação e a qualidade do fogo. Se o fogo é mais intenso e, logo, provoca mais danos onde a vegetação herbácea é mais homogênea, sua atuação impedirá o estabelecimento de grande número de espécies e, desta forma, mantém-se a homogeneidade do estrato herbáceo. Por outro lado, se a intensidade do fogo é maior e mais danosa ao estrato arbóreo/arbustivo, em proporção direta à homogeneidade do estrato herbáceo, e se este estrato é mantido pelo pequeno grau de cobertura arbórea, há novamente uma relação circular, desta vez, entre o estrato herbáceo e o lenhoso.

Mediante análise comparativa com outras regiões do País, denotou-se que tanto o campo cerrado quanto o cerrado sensu stricto possuem pequeno número de espécies lenhosas em comparação com outras áreas pesquisadas (Tab. 6). As savanas de São Paulo foram as que mais se assemelharam floristicamente àquela do Parque. Foi também aparente 


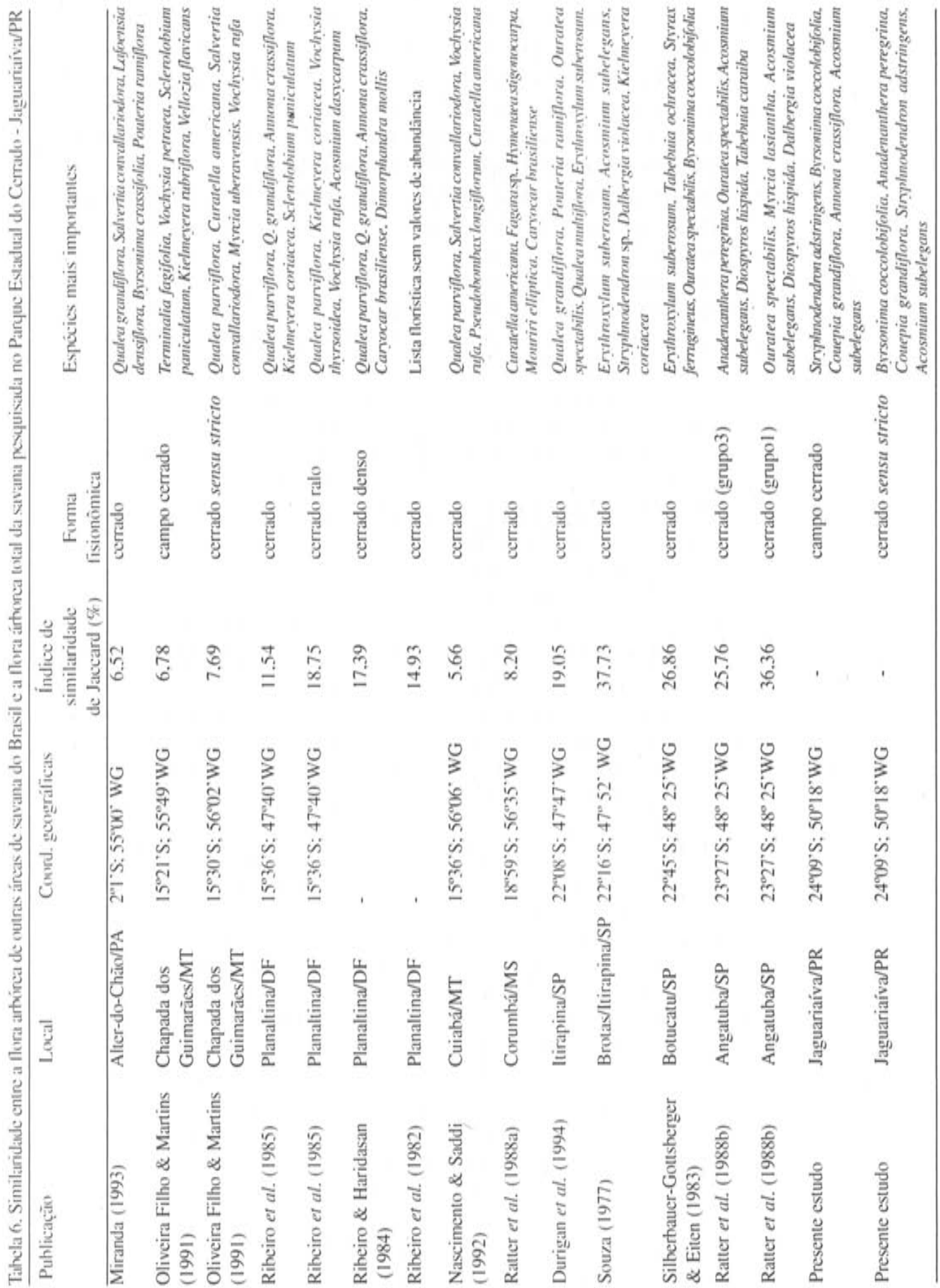


a perda de similaridade na medida em que áreas de savana situadas no Norte ou no Centro-Oeste do Brasil foram tomadas como referência para comparações. A menor similaridade florística com o cerrado de Jaguariaíva foi verificado nas listagens de Cuiabál MT (Nascimento \& Saddi 1992) e Alter-do Chão/PA (Miranda 1993) (Tab. 6).

De fato, notou-se predomínio de Vochysiaceae e Dilleniaceae, sempre representadas nas duas primeiras posições de importância nos cerrados do Norte ou do Centro-Oeste (Tab, 6). Vochysiaceae, representada principalmente por Qualea grandiflora, Q. parviflora, Salvertia convallariodora e Vochysia sp., bem como Dilleniaceae, representada por Curatella americana, podem ser consideradas como famílias muito importantes no conjunto florístico-fisionômico de muitas áreas pesquisadas naquelas regiões. Veloso et al. (1991) citaram os gêneros Vochysia e Qualea, além de Salvertia convallariodora, como elementos característicos da savana, indicando a expansão de Vochysiaceae, família tipicamente amazônica. Esta família, no entanto, não foi bem representada na savana do Parque, e espécies como Vochysia tucanorum e Qualea cordata foram raras na amostragem realizada. Neste estudo, V. tucanorum foi observada com frequiência muito maior em áreas florestais. Q. grandiflora, outra espécie rara, sequer foi amostrada, sendo sua presença registrada através de coleta fora das unidades amostrais. As Leguminosas, por outro lado, foram muito abundantes, confirmando a assertiva de Leitão Filho (1992) no que diz respeito à riqueza específica desta família botânica nos cerrados de São Paulo.

A similaridade florística com áreas de São Paulo já poderia ser esperada em função dos resultados de Castro (1994) e Ratter et al. (1996) que apontaram padrões geográficos marcantes na distribuição da flora das savanas. Ratter et al. (1996) relataram que a quantidade de chuvas e a amplitude do período de seca são fatores de indubitável influência na distribuição da vegetação dos cerrados. Apesar disto, a baixa riqueza da flora lenhosa permanece como questão a ser resolvida, principalmente porque os critérios do estudo não permitiram englobar espécies presentes no Parque (Uhlmann 1995) mas não listadas devido ao seu pequeno porte, o que talvez pudesse ser atribuído ao fogo. Quanto à sua situação periférica, há relatos em literatura (Maack 1968: Leite 1994) que manifestam a opinião de que a ocorrência da savana no Paraná seria relicto de um passado mais seco. Leite (1994) considera um possível avanço de formações florestais sobre a savana. Muito embora as razões pelas quais se dê a permanência da savana não sejam claras, parece razoável aceitar esta hipótese. A ocorrência de geadas, bem como o isolamento das populações presentes, além das interferências antrópicas na região, seriam fatores que pressionariam as populações de algumas espécies, particulamente aquelas menos freqüentes, a seu desaparecimento na comunidade (Eiten 1992). Além disto, a melhor distribuição de chuvas poderia favorecer o avanço de espécies florestais, quando fatores como o fogo não fossem freqüentes o suficiente para limitá-las (Ferri 1973).

\section{Agradecimentos}

Ao CNPq, pela concessão de bolsa; a PISA Florestal S.A. e Prefeitura Municipal de Jaguariaíva, pelo apoio logístico; à Fundação "O Boticário" de Proteção à Natureza, pelo 
financiamento parcial do projeto; ao Curso de Pós-Graduação em Botânica/UFPR, pelo apoio à realização da dissertação; ao Instituto Ambiental do Paraná (em particular aos Srs. Evandro Pinheiro, Juarez Cordeiro e Gerson Jacobs), pela cessão de material e autorização para a realização do trabalho; aos Prof. Dr. Armando C. Cervi e Prof. Dr. Olavo A. Guimarães, pelo auxílio na determinação de várias espécies; ao Prof. Dr. Reinaldo Monteiro, pela leitura crítica do trabalho.

\section{Referências bibliográficas}

Arens, K. 1958. O cerrado como vegetação oligotrófica. Boletim da Faculdade de Filosofia Ciências e Letras - USP 224(15): 59-77.

Bigarella, J. J.; Salamuni, R. \& Marques Filho, P. L. 1966. Estruturas e texturas da Formação Furnas e sua significação paleogeográfica. Boletim da Universidade Federal do Paraná, Geologia 18: 1-114.

Bilbao, B.; Braithwaite, R.; Dall'Aglio, C.; Moreira, A.; Oliveira. P. E.; Ribeiro, J. F. \& Stott, P. 1996. Biodiversity, fire and herbivory in tropical savannas. Pp. 197-203. In O. T. Solbrig; E. Medina \& J. F. Silva (eds.), Biodiversity and savanna ecosystem processes: a global perspective. Springer, Berlin. Brummitt, B. K. \& Powell, C. E. 1992. Authors of plant names. Royal Botanic Gardens, Kew, London.

Castro. A. A. J. F. 1994. Comparação florístico-geográfica (Brasil) e fitossociológica (Piauí-São Paulo) de amostras de cerrado. Tese de Doutorado. Universidade Estadual de Campinas, UNICAMP, Campinas.

Cesar, O.; Pagano, S. N.; Leitão Filho, H. F.; Monteiro, R.; Silva. O. A., Marinis, G. \& Shepherd, G. J. 1988. Estrutura fítossociológica do estrato arbóreo de uma área de vegetação de cerrado no município de Corumbataí (Estado de São Paulo). Naturalia 13: 91-101.

Cole, M. M. 1986. The Savannas: biogeography and geobotany. Academic Press, London.

Coutinho, L. M. 1978. O conceito de cerrado. Revista Brasileira de Botânica 1: 17-23.

Cronquist, A. 1988. The evolution and classification of flowering plants. 2nd edition. The New York Botanical Garden, New York.

Durigan. G.; Leitão Filho, H. F. \& Rodrigues, R. R. 1994. Phytosociology and structure of a frequently burnt cerrado vegetation in SE-Brazil. Flora 189:153-160.

Eiten. G. 1992. Natural Brazilian vegetation types and their causes. Anais da Academia Brasileira de Ciências. 64 (supl. 1): 43-59.

Eiten, G. 1994. Vegetação. Pp. 17-73. In M. N. Pinto (ed.). Cerrado: caracterização, ocupação e perspectivas. $2^{a}$ ed. Editora da Universidade de Brasília. Brasilia.

EMBRAPA - Empresa Brasileira de Pesquisa Agropecuária/SNCLS/SUDESUL/IAPAR. 1984. Levantamento de reconhecimento de solos do Estado do Paraná. SNLCS/SUDESUL/IAPAR. Londrina.

Ferri. M. G. 1973. Sobre a origem, a manutenção e a transformação dos cerrados. Ecologia 1(1): 5-10.

Goodland, R. 1979. Análise ecológica da vegetação do cerrado. Pp. 61-193. In R. Goodland \& M. G. Ferri (eds.), Ecologia do cerrado. Editora da Universidade de São Paulo. São Paulo e Ed. Itatiaia, Belo Horizonte.

Hermann, M. L. P. \& Rosa. R. O. 1990. Relevo. Pp. 55-84. In IBGE. Geografia do Brasil: região sul. IBGE, Rio de Janeiro.

Kauffman, J. B.; Cummings, D. L. \& Ward, D. E. 1994. Relationships of fire, biomass, and nutrient dynamics along a vegetation gradient in the Brazilian cerrado. Journal of Ecology 82: 519-531.

Kaul, P. F. I. 1990. Geologia. Pp. 29-54. In IBGE. Geografia do Brasil: região sul. IBGE, Rio de Janeiro.

Kirk. R. E. 1968. Experimental design procedures for the behavioral sciences. Wadsworth Publishing Company, Inc., Belmont.

Leitão Filho, H. F. 1992. A flora arbórea dos cerrados do Estado de São Paulo. Hoehnea 19(1-2): $151-163$.

Leite. P. F. 1994. As diferentes unidades fitoecológicas da região sul do Brasil, proposta de classificação.

Dissertação de Mestrado. Universidade Federal do Paraná, Curitiba.

Maack. R. 1968. Geografia física do Estado do Paraná. Livraria José Olympio Editora, Rio de Janeiro e Secretaria da Cultura e do Esporte do Governo do Estado do Paraná, Curitiba.

Magurran, A. E. 1989. Diversidad ecologica y su medición. Ed. Vedra. Barcelona. 
Miranda. I. 1993. Estrutura do estrato arbóreo do cerrado amazônico em Alter-do-Chão, Pará, Brasil. Revista Brasileira de Botânica 16(2): 143-150.

Mueller-Dombois, D. \& Ellenberg. H. 1974. Aims and methods of vegetation ecology. John Wiley \& Sons. New York.

Nascimento, M. T. \& Saddi, N. 1992. Structure and floristic composition in an area of cerrado in CuiabáMT. Revista Brasileira de Botânica 15(1): 47-55.

Oliveira Filho, A. T.\& Martins. F. R. 1986. Distribuição, caracterização e composição florística das formações vegetais da região de Salgadeira, na Chapada dos Guimarães (MT). Revista Brasileira de Botânica 9: 207-223.

Oliveira Filho, A. T.; Shepherd. G. J.; Martins, F. R. \& Stubblebine. W. H. 1989. Environmental factors affecting physiognomic and floristic variation in an area of cerrado in central Brazil. Journal of Tropical Ecology 5: 413-431.

Pielou. E. C. 1975. Ecological diversity. John Wiley \& Sons. New York.

Ratter. J. A. 1987. Notes on the vegetation of the Parque Nacional do Araguaia (Brazil). Notes of Royal Botanical Gardens Edinburgh 44(2):311-342.

Ratter, J. A.; Pott, A.; Pott, V. J.; Cunha, C.N. \& Haridasan. M. 1988a. Observation on woody vegetation types in the pantanal and at Corumbá, Brazil. Notes of Royal Botanical Gardens Edinburgh 45 (3): 503-525.

Ratter, J. A.; Leitão Filho, H. F.; Argent, G.; Gibbs, P. E.: Semir. J.; Shepherd, G. J. \& Tamashiro, J. 1988b. Floristic composition and community structure of a southern cerrado area in Brazil. Notes of Royal Botanical Gardens Edinburgh 45 (1):137-152.

Ratter. J. A. \& Dargie. T. C. D. 1992. An analysis of the floristic composition of 26 cerrado areas in Brazil. Edinburgh Journal of Botany 49 (2): 235-250.

Ratter. J. A.; Bridgewater. S.; Atkinson, R. \& Ribeiro. J. F. 1996. Analysis of the floristic composition of the Brazilian cerrado vegetation II: comparison of the woody vegetation of 98 areas. Edinburgh Journal of Botany 53: 153-180.

Ribeiro, J. F.; Silva, J. C. S. \& Azevedo, L. G. 1982. Estrutura e composição florística em tipos fisionômicos dos cerrados e sua interação com alguns parâmetros do solo. Pp. 141-156. Anais do XXXII Congresso Nacional de Botânica. Teresina 1981. Sociedade Botânica do Brasil, São Paulo.

Ribeiro. J. F. \& Haridasan. M. 1984. Comparação fitossociológica de um cerrado denso e um cerradão em solos distróficos no Distrito Federal. Pp. 342-353. Anais do XXXV Congresso Nacional de Botânica, Manaus, 1984. Sociedade Botânica do Brasil. São Paulo.

Ribeiro, J. F.; Silva, J. C. S. \& Batmannian G. J. 1985. Fitossociologia de tipos fisionômicos de cerrado em Planaltina/DF. Revista Brasileira de Botânica 8: 131-142.

Rizzini, C. T. 1963. A flora do cerrado: análise florística das savanas centrais. Pp. 125-177. In M. G. Ferri (ed.). Simpósio sobre o cerrado. Ed. Edgar Blücher, São Paulo.

Schobbenhaus, C.; Campos. D. A.; Derze, G. R. \& Asmus. H. E. 1984. Geologia do Brasil. Departamento Nacional de Produção Mineral - DNPM/ Divisão de Geologia e Mineralogia, Brasília.

Silberbauer-Gottsberger, 1.; Eiten. G. 1983. Fitossociologia de um hectare de cerrado. Brasil Florestal 54: 55-70.

Souza. M. H. A. O. 1977. Alguns aspectos da vegetação na região perimetral da represa do Lobo (Brotas-Itirapina/SP). Tese de Doutorado. Universidade de São Paulo, São Paulo.

Toledo Filho, D.V. 1984. Composição florística e estrutura fitossociológica da vegetação de cerrado no Município de Luís Antônio (SP). Dissertação de Mestrado. Universidade Estadual de Campinas, UNICAMP, Campinas.

Uhlmann. A. 1995. Análise fitossociológica de três categorias fitofísionômicas no Parque Estadual do Cerrado - Jaguariaíva/PR. Dissertação de Mestrado. Universidade Federal do Paraná, Curitiba.

Uhlmann, A.; Curcio, G.R.: Galvão, F. \& Silva, S.M. 1997. Relaçôes entre a distribuição de categorias fitofisionômicas e padrões geomórficos e pedológicos em uma área de savana (cerrado) no Estado do Paraná, Brasil. Arquivos de Biologia e Tecnologia 40(2): 473-484.

Veloso, H.P.: Rangel Filho, A.L.R. \& Lima, J.C.A. 1991. Classificação da vegetação brasileira adaptada a um sistema universal. IBGE, Departamento de Recursos Naturais e Estudos Ambientais, Rio de Janeiro.

Warming, E. 1908. Lagoa Santa. Imprensa Olicial do Estado de Minas Gerais, Belo Horizonte. 